\title{
Research Regarding the Antimicrobial Activity of Plant Extracts
}

\author{
Steliana RODINO*1, 2), Marian BUTU²), Georgeta FIDLER ${ }^{1,2)}$, Alina BUTU²), \\ Constanta NEGOESCU ${ }^{3)}$, Calina P. CORNEA ${ }^{1)}$ \\ ${ }^{1)}$ University of Agronomic Science and Veterinary Medicine, 59 Marasti Bv., 011464 Bucharest, \\ Romania \\ ${ }^{2)}$ National Institute of Research and Development for Biological Sciences, 296 Splaiul Independentei, \\ 060031 Bucharest, Romania \\ ${ }^{3}$ Banat's University of Agricultural Sciences and Veterinary Medicine "Regele Mihai I al României" \\ from Timişoara, 119 Aradului Road, 300645 Timişoara, Romania \\ *Corresponding authors, email: steliana.rodino@yahoo.com; marian_butu@yahoo.com
}

Bulletin UASVM Animal Science and Biotechnologies 72(1) / 2015

Print ISSN 1843-5262; Electronic ISSN 1843-536X

DOI:10.15835/buasvmen-asb:10569

\begin{abstract}
The investigations regarding the use of plant extracts for their antimicrobial activity is becoming more intense nowadays. The goal of this paper was to evaluate the antimicrobial activity of several plant extracts in order to provide a better understanding of the essential role of the use of plant natural compounds as a primary source of antimicrobial products. Hydroalcoholic extracts of five medicinal plants were tested for their antimicrobial activity against Pythium sp. The plants considered for study were marigold (Tagetes patula), horsetail (Equisetum arvense), elderberry (Sambucus nigra), burdock (Arctium lappa) and liquorice (Glycyrrhiza glabra). The plant materials used for extractions were obtained from healthy dried plants collected from natural populations on non-polluted lands. The experiments demonstrated that plants possess strong antimicrobial activity and that plant based products can be effective in controlling microbial growth inhibition. Plant extracts may potentially control the growth and development of pathogenic microorganisms thus representing an alternative in plant protection management and human and veterinary medicine also.
\end{abstract}

Keywords: antimicrobial activity, pathogenic microorganisms, plant extracts

\section{INTRODUCTION}

From ancient to modern history, various traditional plant based products played a major role in healthcare and phytopathology (Prasad and Aggarwal, 2011; Vasanthi et al., 2012). Lately, researchers from various fields such as chemistry, microbiology, pharmacology, agriculture and horticulture are investigating natural sources to find phytochemicals that may be used in the development of new antimicrobial products (Evans and Cowan, 2006). Medicinal and aromatic plants are presently the most investigated vegetal sources for their potential antimicrobial activity and its applicability. Moreover, it is considered that the plant kingdom offers many biochemicals that can be used as pesticides, which are more environmentally safe than the synthetic chemicals (Riaz et al., 2010). Pesticides based on natural components used in plant disease management gained increased attention lately, in search for ecofriendly methods that can be used complementary, either for mass production or for the organic and biofarming niche production.

Natural products derived from plants are considered a solution to mitigate the environmental issues caused by the intensive use 
of synthetic pesticides and the negative effects on the human health through the food chain (Rodino et al., 2014). Consequently, the current research is targeted on developing alternative treatments to synthetic chemicals for plant disease control.

Pythium species can cause serious diseases such as damping off, seed rot, root rot and soft rot (Agrios, 2005; Homer et al., 2012; Le et al., 2014) in wheat (Triticum aestivum), maize (Zea mays), soybean (Glycine max), peppers (Capsicum annuum.), beans (Pisum sativum), cucumber (Cucumis sativus), tomato (Solanum lycopersicum), and many other crops resulting in significant economic losses. Chemical treatments with pesticides together with integrated disease management methods used for control of Pythium diseases seem not to be completely effective, and therefore it is recognized as a major pathogen of various crops and the diseases it causes remains a persistent issue for the farmers to deal with (AlSheikh, 2010).

In the present study, hydroalcoholic extracts of five medicinal plants were tested for their antifungal activity against Pythium sp. The plants taken into study were marigold (Tagetes patula), horsetail (Equisetum arvense), elderberry (Sambucus nigra), burdock (Arctium lappa) and liquorice (Glycyrrhiza glabra).

\section{MATERIALS AND METHODS}

Plant material. The medicinal plants used in this study were selected from the locally available spontaneous flora and used as presented in Table 1. The plant materials used for extractions were obtained from healthy dried plants collected from natural populations on non-polluted lands from Southern Romania. The plant parts were chosen according to the traditional medicinal use of the refereed plants.

Preparation of plant extracts. A quantity of 10 grams of dried and powdered plant material was added to $100 \mathrm{ml}$ of $70 \%$ ethanol. The mixture was left in sealed glass recipients for 96 hours, at room temperature, in darkness, with occasionally stirring. The obtained extract was filtrated through filter paper (Whatman no.1) under vacuum. The extracts obtained were kept at $4{ }^{\circ} \mathrm{C}$ in sealed recipients until further use.

Fungal culture and growth conditions. The fungal strain of Pythium sp. belongs to the collection of the Faculty of Biotechnologies from the University of Agronomic Sciences and

Tab. 1. Plant material used for study.

\begin{tabular}{|c|c|c|c|c|c|}
\hline & $\begin{array}{l}\text { Popular } \\
\text { name }\end{array}$ & $\begin{array}{l}\text { Botanical } \\
\text { name }\end{array}$ & Family & $\begin{array}{l}\text { Part } \\
\text { used }\end{array}$ & Uses in traditional medicine \\
\hline 1. & Marigold & $\begin{array}{l}\text { Tagetes } \\
\text { patula }\end{array}$ & Asteraceae & Flowers & $\begin{array}{c}\text { gastric ulcers, conjunctivitis, } \\
\text { bronchitis, fever, inflammation } \\
\text { and wounds } \\
\text { (Marottia et al., 2011) }\end{array}$ \\
\hline 2. & Liquorice & $\begin{array}{c}\text { Glycyrrhiza } \\
\text { glabra }\end{array}$ & Fabaceae & Roots & $\begin{array}{l}\text { eczema, peptic ulcers, upper } \\
\text { respiratory infections } \\
\text { (Fiore et al., 2005) }\end{array}$ \\
\hline 3. & Burdock & $\begin{array}{l}\text { Arctium } \\
\text { lappa }\end{array}$ & Asteraceae & Leaves & $\begin{array}{c}\text { skin infections, acne, boils, bites, } \\
\text { eczema, herpes } \\
\text { (Nejad et al., 2012) }\end{array}$ \\
\hline 4. & Horsetail & $\begin{array}{l}\text { Equisetum } \\
\text { arvense }\end{array}$ & Equisetaceae & $\begin{array}{l}\text { Whole } \\
\text { Plant }\end{array}$ & $\begin{array}{c}\text { disorders of the skin, kidneys } \\
\text { and urinary tract } \\
\text { (Brunet et al., 2009) }\end{array}$ \\
\hline 5. & Elderberry & $\begin{array}{l}\text { Sambucus } \\
\text { nigra }\end{array}$ & Caprifoliaceae & Fruits & $\begin{array}{c}\text { antitumor potential, } \\
\text { antimicrobial, fungistatic, } \\
\text { antioxidant activity } \\
\text { (Barros et al., 2011; Sidor and } \\
\text { Gramza-Michalowska, 2014; } \\
\text { Vlachojannis et al., 2011) }\end{array}$ \\
\hline
\end{tabular}


Veterinary Medicine of Bucharest. The fungal culture was maintained on potato dextrose agar (PDA) at $20^{\circ} \mathrm{C}$. The antimicrobial tests were carried out using mycelial plugs originating from an actively growing culture.

Evaluation of the antimicrobial activity. The effect of the different concentrations of the selected plant extracts against the mycelial growth of Pythium sp. was tested by poisoned food technique. An appropriate quantity of each extract was incorporated in sterilized PDA medium to reach desired concentrations for each treatment. Three concentrations of ethanolic extracts were used in the assessment, respectively, $1 \%, 0.5 \%$ and $0.25 \%$. Untreated PDA plates represented the positive control. The plates were left to solidify in the laminar flow hood and then mycelial discs of 6 mm diameter, taken from the margins of an actively growing culture of the phytopathogen were placed in the center of each Petri plates. Three replicates were used for each treatment. The Petri plates were incubated in dark at $25 \pm 2^{\circ} \mathrm{C}$ until the control colony reached the margins of the Petri plate. The measurement of the diameter of the mycelial growth was recorded on a daily basis, beginning with 24 hours after inoculation. The percentage of the growth inhibition of the mycelium (I) due to treatment with extracts was calculated using the following formula:

$\mathrm{I}(\%)=(1-\mathrm{dt} / \mathrm{dc}) * 100(\%)$,

where, dc is the average fungal colony diameter measured in control plate, with no treatment, and $\mathbf{d t}$ is the average fungal colony diameter measured in treated plates.

Statistical analysis. The experimental data were subjected to one-way analysis of variance (ANOVA) using Microsoft Excel 2010.

\section{RESULTS AND DISCUSSION}

Pythium sp. in vitro growth proved to be sensitive to treatment with most of the plant extracts, demonstrated by the inhibition of the mycelial growth. The results revealed that the antimicrobial activity of the extracts was dose dependent, being negatively influenced by decreasing the concentration of the extracts in the growth media.

Regarding the growth inhibition dynamics of the variant using $1 \%$ extract concentration in the culturing medium it could be observed a delayed development of the Pythium sp. inoculum compared to the not treated control. The mycelium started to develop on the control plates ten to twelve hours after inoculation and grew rapidly reaching the margins of the Petri plate in four days. On the treated plates, the growth was only observed after 24 hours since inoculation. The daily measurements of the radial growth of Pythium sp. colony at $1 \%$ concentration in the culture media are presented in Figure 1. At this concentration, the strongest extracts with more than 50\% inhibition against Pythium sp. were G. glabra extract, with $72 \%$ growth inhibition, followed by T. patula 56\%. The other three plant extracts showed an inhibition percentage below $50 \%$ as follows: E. arvense $46 \%$, and S. nigra and respectively, A. lappa $2.4 \%$ (Fig. 2).

Going further to a $0.5 \%$ concentration of the plant extract, the inhibition of growth decreased, reaching 49\% for G. glabra and 38\% for T. patula. In this variant on the plates treated with extracts obtained from burdock, horsetail and elderberry the colonies had a slower growth than the control, but at the end of the 96 hours of incubation, they reached the margins of the plate. For a concentration of $0.25 \%$ the results are comparable. In the fourth day, the diameter of the colony treated with licorice being $48 \mathrm{~cm}$ corresponding to $\mathrm{I}=32 \%$. For marigold, the mean diameter measured was $49 \mathrm{~cm}, \mathrm{I}=30 \%$.

From these results it can be concluded that the extract of marigold (T. patula) and licorice (G. glabra) possesses strong in vitro antifungal activity against Pythium sp. and can be subjected to further investigation regarding their chemical composition and their antimicrobial potential for in vivo efficacy study.

Occurrence of several active compounds, most of them terpenoids and flavonoids has been reported from these two plants. These compounds are known to exhibit antioxidant, antifungal, antibacterial and analgesic activities (Pérez Gutiérrez et al., 2006; Barnabas et al. 1988). Many biological activities, such as anti-inflammatory, anti-viral, antitumour and hepatoprotective drug, antifungal, antioxidant, anti-atherogenic, anti-genotoxic have been reported for G. glabra extracts (Fatima et al., 2009; Evans and Cowan, 2006; Visavadiya et al., 2009; Siracusa et al., 2011). These activities were reported due to two kinds of main constituents, the saponins and flavonoids present in G. glabra (Patil et al., 2009). 


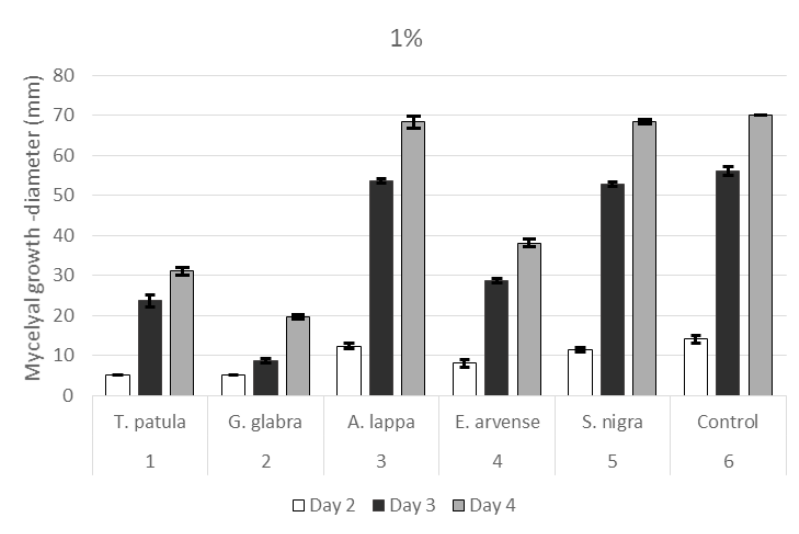

Fig. 1. Diameter growth of Pythium sp. colony on PDA after treatment with plant extracts at $1 \%$ concentration.

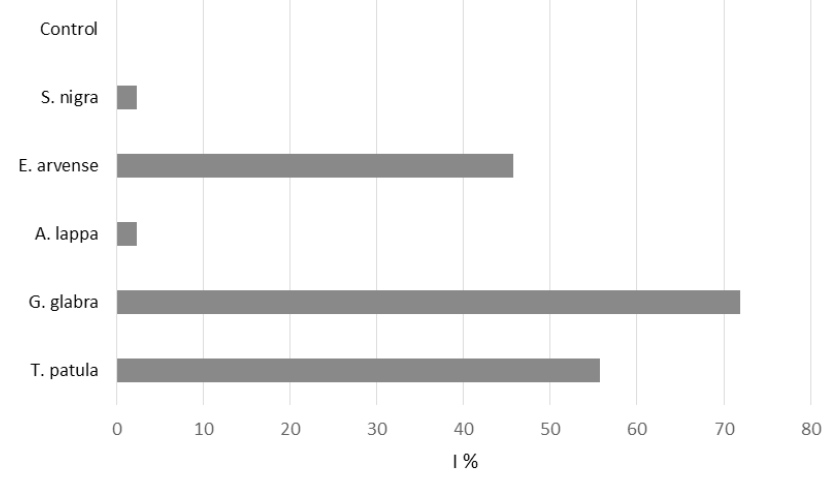

Fig. 2. Percentage of the growth inhibition of the mycelium (I) due to treatment with extracts.

The phytochemical investigation of different parts of T. patula resulted in the isolation of the chemical constituents of several classes of secondary metabolites, such as flavonoids, benzofurans, carotenoids and thiophenes (Politi et al., 2012; Marottia et al., 2004). Other previous studies on the phytochemical composition of ethanolic floral extract of T. patula showed the presence of alkaloids, flavonoids, tannins and phenolics (Ramya et al., 2012; Trombetta et al., 2005). There are other previous reports on antimicrobial action of plants extracts against different Pythium species. Muthukumar et al. (2010) evaluated the fungitoxic effects of 66 medicinal plants against Pythium aphanidermatum, the causal agent of chilli damping-off. According to their findings, Zimmu leaf extract (Allium sativum L. $\times$ Allium cepa L.) showed the highest inhibition of mycelial growth of P. aphanidermatum (13.7 mm) (Muthukumar et al., 2010). Ambikapathy et al. (2011) reported maximum antifungal activity (15 and $20 \mathrm{~mm}$ ) of the n-butanol and methanol extract of Lawsonia inermis, followed by Phyllanthus niruri (15 and 20 $\mathrm{mm}$ ), Tephrosia purpurea (10 and $15 \mathrm{~mm}$ ) against Pythium debaryanum. The methanolic extract of Mimosa pudica $(20 \mathrm{~mm})$, Vinca rosea $(10 \mathrm{~mm})$ exhibited least activity against $P$. debaryanum. He also tested the antifungal effect of aqueous extract of all tested five plants but these ones showed no activity against $P$. debaryanum (Ambikapathy et al., 2011).

Crude aqueous and methanolic extracts of 97 plant species belonging to 35 families collected from the west of Iran, were screened for antifungal activity against Pythium aphanidermatum by Bahraminejad (2012). Seventeen of 97 (17.5\%) plant species showed inhibitory activity against the tested fungi. Glycyrrhiza glabra, Xanthium strumarium and Portulaca oleraceae were among the active plant species against $P$. aphanidermatum. The efficacy of the selected plant crude extracts against $P$. aphanidermatum was also evaluated in greenhouse condition and all tested plant extracts were reported to show superior effect in reducing the disease severity as compared to the control. Among the different treatments, seed treatments of G. glabra and P. oleraceae extracts reduced disease severity from $70 \%$ for infected control to 43\% (Bahraminejad, 2012).

\section{CONCLUSION}

From the results, it can be concluded that the extract of flowers of marigold (T. patula) and roots of licorice (G. glabra) possesses strong in vitro antifungal activity against Pythium $s p$. and should be subjected to further investigation regarding their chemical composition, mechanism of action and their antimicrobial potential for in vivo efficacy study.

Plant extracts may potentially control the growth and development of pathogenic microorganisms thus representing an alternative in plant protection management and human and veterinary medicine also. These findings provide a basis for the use of naturally occurring compounds in the design of new solutions for pathogens control. 
Acknowledgments. This paper was published under the frame of European Social Fund, Human Resources Development Operational Programme 2007-2013, project no. POSDRU/159/1.5/S/ 132765 and by UEFISCDI research contract PN-IIPT-PCCA 106/2012.

\section{REFERENCES}

1. Agrios GN (2005). Plant Pathology, Fifth edition, Elsevier Academic Press Inc., New York.

2. Al-Sheikh H (2010). Two pathogenic species of Pythium: P. aphanidermatum and $P$. diclinum from a wheat field, Saudi Journal of Biological Sciences, 17(4): 347-352.

3. Ambikapathy V, Gomathi S and Panneerselvam A (2011). Effect of antifungal activity of some medicinal plants against Pythium debaryanum (Hesse), Asian Journal of Plant Science and Research, 1(3): 131-134.

4. Bahraminejad S (2012). In vitro and in vivo antifungal activities of Iranian plant species against Pythium aphanidermatum, Annals of Biological Research, 3(5): 2134-2143.

5. Barnabas CG, Nagarajan S (1988). Antimicrobial activity of flavonoids of some medicinal plants, Fitoterapia, 3:508510.

6. Barros L, Cabrita L, Vilas Boas, M, Carvalho AM, Ferreira I and Isabel CFR (2011). Chemical, biochemical and electrochemical assays to evaluate phytochemicals and antioxidant activity of wild plants, Food Chemistry, 127(4): 1600-1608.

7. Čanadanović-Brunet JM, Ćetković GS, Djilas SM, Tumbas VT, Savatović SS, Mandić AI, Markov SL and Cvetković DD (2009). Radical scavenging and antimicrobial activity of horsetail (Equisetum arvense L.) extracts, International Journal of Food Science \& Technology, 44: 269-278.

8. Evans SM and Cowan MM (2006). Plant Products as Antimicrobial Agents, Chapter 13 in Book: Cosmetic and Drug Microbiology, Informa Healthcare.

9. Fatima A, Gupta VK, Luqman S, Negi AS, Kumar JK, Shanker K and Khanuja SP (2009). Antifungal activity of Glycyrrhiza glabra extracts and its active constituent glabridin, Phytotherapy Research, 23(8), 1190-1193.

10. Fiore C, Eisenhut M, Ragazzi E, Zanchin G and Armanini D (2005). A history of the therapeutic use of liquorice, Europe. J Ethnopharmacol. 99(3): 317-324.

11. Horner N, Grenville-Briggs L, van West P (2012). The oomycete Pythium oligandrum expresses putative effectors during mycoparasitism of Phytophthora infestans and is amenable to transformation, Fungal Biology, 116(1): 24-41.

12. Le DP, Smith M, Hudler GW and Aitken E (2014). Pythium soft rot of ginger: Detection and identification of the causal pathogens, and their control, Crop Protection, 65:153-167.

13. Marottia M, Piccagliaa R, Biavatia B and Marottia I (2004). Characterization and Yield Evaluation of Essential Oils from Different Tagetes Species, Journal of Essential Oil Research, 16(5): 440-444.
14. Muthukumar A, Eswaran A, Nakkeeran $S$ and Sangeethaa G (2010). Efficacy of plant extracts and biocontrol agents against Pythium aphanidermatum inciting chilli dampingoff, Crop Protection, 29(12): 1483-1488.

15. Nejad ASM, Kamkar A, Giri A and Pourmahmoudi AA (2013). Ethnobotany and folk medicinal uses of major trees and shrubs in Northern Iran, J Medicinal Plants Research, 7(7): 284-289.

16. Patil SM, Patil MB and Sapkale GN (2009). Antimicrobial activity of Glycyrrhiza glabra linn. Roots, Int. J. Chem. Sci, 7(1): 585-591.

17. Pérez Gutiérrez R, Hernández Luna $H$ and Garrido $S H$ (2006). Antioxidant activity of Tagetes erecta essential oil, Journal of the Chilean chemical Society, 51(2), 883-886.

18. Politi FAS, Figueira GM, Araújo AM, Sampieri BR, Mathias MIC, Szabó MPJ, Bechara GH, Dos Santos LC, Vilegas W and Pietro RCLR (2012). Acaricidal activity of ethanolic extract from aerial parts of Tagetes patula L. (Asteraceae) against larvae and engorged adult females of Rhipicephalus sanguineus (Latreille, 1806), Parasites \& Vectors, 5:295.

19. Prasad S, Aggarwal BB (2011). Turmeric, the Golden Spice: From Traditional Medicine to Modern Medicine, Chapter 13 in: Benzie, I.F.F. and Wachtel-Galor, S., editors. Herbal Medicine: Biomolecular and Clinical Aspects. 2nd edition. Boca Raton (FL): CRC Press.

20. Ramya R, Mahna S, Bhanumathi SP and Bhat SK (2012). Analysis of phytochemical composition and bacteriostatic activity of Tagetes sp., Int. Res. Journal of Pharmacy, 3 (11): 114-115.

21. Riaz T, Kha SN and Javaid A (2010). Management of cormrot disease of Gladiolus by plant extracts, Natural Product Research 24(12): 1131-1138.

22. Rodino S, Butu M, Petrache P, Butu A and Cornea CP (2014). Antifungal activity of four plants against Alternaria Alternata. Scientific Bulletin. Series F. Biotechnologies, Vol. XVIII, 60-65.

23. Sidor A and Gramza-Michałowska A (2014). Advanced research on the antioxidant and health benefit of elderberry (Sambucus nigra) in food - a review, Journal of Functional Foods, available online 5 August 2014 In Press.

24. Siracusa L, Saija A, Cristani M, Cimino F, D’Arrigo M, Trombetta D and Ruberto G (2011). Phytocomplexes from liquorice (Glycyrrhiza glabra L.) leaves -Chemical characterization and evaluation of their antioxidant, antigenotoxic and anti-inflammatory activity, Fitoterapia, 82(4), 546-556.

25. Trombetta D, Castelli F, Sarpietro MG, Venuti V, Cristani M, Daniele C, Saija A, Mazzanti G and Bisignano G ( 2005). Mechanisms of antibacterial action of three monoterpenes, Antimicrob Agents Chemother, 49(6): 2474-2478.

26. Visavadiya NP, Soni B and Dalwadi N (2009). Evaluation of antioxidant and anti-atherogenic properties of Glycyrrhiza glabra root using in vitro models, International Journal of Food Sciences and Nutrition, 60(S2), 135-149.

27. Vlachojannis JE, Cameron M and Chrubasik S (2010). A systematic review on the sambuci fructus effect and efficacy profiles, Phytother Res. 24(1): 1-8. 